\title{
Awareness and Perception of Epidural Labor Analgesia Amongst Parturient in South Eastern Nigeria
}

\author{
Fidelis Anayo Onyekwulu ${ }^{1,}$, , Innocent Chidiebere Ugwu ${ }^{1}$, Elias Chikee Aniwada ${ }^{2}$, \\ Tochukwu Christopher Okeke ${ }^{3}$ \\ ${ }^{1}$ Department of Anaesthesia, University of Nigeria Teaching Hospital, Ituku Ozalla, Enugu, Nigeria \\ ${ }^{2}$ Department of Community Medicine, University of Nigeria Teaching Hospital, Ituku Ozalla, Enugu, Nigeria \\ ${ }^{3}$ Department of Obstetric and Gynaecology, University of Nigeria Teaching Hospital, Ituku Ozalla, Enugu, Nigeria
}

Email address:

faonyekwulu@yahoo.com (F. A. Onyekwulu), talktomedrugwu@yahoo.com (I. C. Ugwu), eaniwada@gmail.com (E. C. Aniwada), tcokeke2014@yahoo.com (T. C. Okeke)

${ }^{*}$ Corresponding author

\section{To cite this article:}

Fidelis Anayo Onyekwulu, Innocent Chidiebere Ugwu, Elias Chikee Aniwada, Tochukwu Christopher Okeke. Awareness and Perception of Epidural Labor Analgesia Amongst Parturient in South Eastern Nigeria. Clinical Medicine Research. Vol. 6, No. 3, 2017 , pp. 116-120. doi: $10.11648 /$ j.cmr.20170603.20

Received: February 20, 2017; Accepted: March 27, 2017; Published: May 25, 2017

\begin{abstract}
This study was carried out to assess the awareness, perceptions, acceptance, and the level of utilization of epidural analgesia in relation to other methods of labor pain relief among prospective parturient attending the ante-natal clinic in south eastern Nigeria. Women attending the ante-natal clinic were interviewed using interviewer administered questionnaires containing both open and closed questions, to evaluate their awareness, perceptions, acceptance and level of utilization of labor analgesia in general and epidural analgesia in particular. Data were analysed using SPSS Statistics Version 21.0. The study included 150 women with mean age of $29.63 \pm 5.02$. Most of the respondents $(94.7 \%)$ had at least secondary school education. More than half the respondents (62.7\%) knew about labor analgesia and 38.7\% knew about epidural labor analgesia. Source of knowledge to vast majority $(75.6 \%)$ were doctors and nurses. Majority of the multiparous respondents $(81.27 \%)$ had moderate or severe pain in the previous confinement and only $53 \%$ had pain relieve. Of those who had pain relieve, two third hard breathing exercises while $4.8 \%$ had epidural analgesia. Majority of the respondents $(72.7 \%)$ would want to have labor analgesia, and $53.3 \%$ desired epidural in their next delivery. There is poor level of awareness and utilization of epidural labor analgesia by women attending an antenatal clinic in south eastern Nigeria.
\end{abstract}

Keywords: Epidural Analgesia, Labor Pain, Awareness and Perception

\section{Introduction}

Labor is seen as excruciatingly painful among most Nigerian women [1-5]. The pain of labor is not known to be beneficial to the process of labor; and it can be a source of extreme discomfort to the parturient [4].

Pain relief in labor has developed gradually since Simpson's discovery of chloroform for labor analgesia in 1847 [6, 7]. Today various pharmacological and nonpharmacological methods are in use for labor analgesia with varying degrees of success. Non-pharmacological methods of labor analgesia include breathing exercise, hypnosis, transcutaneous electrical nerve stimulation (TENS), low back massage, acupuncture and supportive care. Pharmacological methods include parenteral opioids, inhalational agents, and epidural analgesia [4-7]. Epidural analgesia is seen as the gold standard for labor pain relief in the modern obstetric practice [8].

The evolution of labor analgesia is not only in the methods but also in the "medical profession's perspective of pain management from simply good practice to an imperative founded on patients' rights" $[4,8,9]$.

Studies on the level of awareness, perception, attitude and use of epidural analgesia for labor pain relief show that awareness and utilization of epidural labor analgesia is still very low in developing countries $[6,7,10-15]$. 
With epidural analgesia as the gold standard of labor pain relief [8], and pain relief seen not only as good practice but patients' right [4, 9], the question becomes, 'how far has epidural analgesia for labor evolved in the south eastern part of Nigeria?'

The aim of this study was to assess the awareness, perceptions, acceptance, and the level of utilization of epidural analgesia in relation to other methods of labor pain relief among prospective parturient attending the ante-natal clinic in Nigeria.

\section{Patients and Methods}

\subsection{Study Location}

The study was carried out at the University of Nigeria Teaching Hospital Enugu Nigeria. It is a 700 bedded multispecialist hospital and it's a referral centre for the south eastern region of the country.

\subsection{Consent}

After ethical clearance from the hospital's Health Research and Ethics Committee and informed consent from participants, 150 consecutive women attending the antenatal clinic from 2nd March 2016 to 24th April 2016 and willing to participate were selected and interviewed. Women who had caesarean section in the previous confinement were excluded from the study.

\subsection{Data Collection}

The interview was conducted using interviewer administered structured questionnaire. The questionnaires were written in English. Vernacular translations were provided for respondents with limited education. Verbal explanation of the concept of epidural labor analgesia was also given to respondents who asked.

Questions were asked about respondents' sociodemographic data, knowledge of labor analgesia, types of labor analgesia known, source of knowledge, rating of pain and use of pain relieve in the previous delivery, desire to have pain relief in labor, awareness and desire to have epidural analgesia in labor.

\subsection{Data Analysis}

Statistical analysis was done using IBM SPSS Statistics for Windows, Version 21.0. Responses to questions were presented in tables. Level of awareness of methods of labor analgesia was compared among the socio-demographic groups using chi-square test. $\mathrm{P}$ value less than 0.05 was considered statistically significant.

\section{Results}

The mean age of the respondents was $29.63 \pm 5.02$ years. Most of the women $(94.7 \%)$ had at least secondary school education, and (92.7\%) were married and living with spouse.
Of the 117 multigravida respondents, 89(76\%) had their last confinement in a private or a tertiary hospital (Table 1).

Table 1. Socio-demographics of respondents.

\begin{tabular}{|c|c|c|}
\hline & Frequency & Percentage \\
\hline \multicolumn{3}{|l|}{ Age in categories (yrs) } \\
\hline$\leq 30$ & 88 & 58.7 \\
\hline$>30$ & 62 & 41.3 \\
\hline Mean (SD) & $29.63(5.02)$ & \\
\hline \multicolumn{3}{|l|}{ Marital Status } \\
\hline Married with spouse & 139 & 92.7 \\
\hline Others & 11 & 7.3 \\
\hline \multicolumn{3}{|l|}{ Tribe } \\
\hline Igbo & 141 & 94 \\
\hline Others & 9 & 6.0 \\
\hline \multicolumn{3}{|l|}{ Educational Level } \\
\hline Primary and below & 8 & 5.3 \\
\hline Secondary and above & 142 & 94.7 \\
\hline \multicolumn{3}{|l|}{ Employment } \\
\hline Unemployed & 38 & 25.3 \\
\hline Employed & 112 & 74.7 \\
\hline \multicolumn{3}{|l|}{ Religion } \\
\hline Christianity & 145 & 96.7 \\
\hline Others & 5 & 3.3 \\
\hline \multicolumn{3}{|l|}{ Gravidity } \\
\hline 1 & 33 & 22.0 \\
\hline 2 & 82 & 54.7 \\
\hline$\geq 3$ & 35 & 23.3 \\
\hline $\operatorname{Mean}(\mathrm{SD})$ & $1.64(1.27)$ & \\
\hline \multicolumn{3}{|c|}{ Place of last confinement $n=117^{*}$} \\
\hline Home & 3 & 2.6 \\
\hline TBA & 3 & 2.6 \\
\hline Private hospital & 41 & 35.0 \\
\hline PHC & 8 & 6.8 \\
\hline SHC & 14 & 12.0 \\
\hline THC & 48 & 41.0 \\
\hline
\end{tabular}

TBA- traditional birth attendants, PHC- primary health care centre, SHCsecondary health care centre, THC- tertiary health care centre.

*Number of respondents that had previous confinement (delivery).

The women's awareness of any pain relief in labor, the type of pain relief available and the sources of their knowledge are shown in Table 2. More than half of the respondents (62.7\%) know about labor analgesia. About $75.6 \%$ of the women received information about pain relief from hospital staff, and breathing exercise $(64.9 \%)$ is the most widely known type. Others include injection (59.6\%) and epidural (38.3\%).

Table 2. Knowledge of analgesia in labor.

\begin{tabular}{lll}
\hline & Number (\%) & Number (\%) \\
\hline & Yes & No \\
\hline Awareness of any pain relief in labor & $94(62.7)$ & $56(37.3)$ \\
Types you know about $\mathrm{n}=94^{*}$ & Yes & No \\
Injection & $56(59.6)$ & $38(40.4)$ \\
Breathing exercise & $61(64.9)$ & $33(35.1)$ \\
Epidural analgesia & $36(38.3)$ & $58(61.7)$ \\
Others & $7(7.4)$ & $87(92.2)$ \\
Source of Knowledge (First) $\mathrm{n}=94^{*}$ & Frequency & $(\%)$ \\
\hline
\end{tabular}




\begin{tabular}{lll}
\hline & Number (\%) & Number (\%) \\
\hline & Yes & No \\
\hline Doctor & 42 & $(44.7)$ \\
Nurse & 29 & $(30.9)$ \\
Friends/relatives & 10 & $(10.6)$ \\
Textbook & 9 & $(9.6)$ \\
Media & 4 & $(4.3)$ \\
\hline
\end{tabular}

*Number of respondents that are aware of pain relief in labor.

Majority $(81.2 \%)$ of the multigravida respondents had moderate or severe pain in the previous confinement, and only about half of them had pain relieve (Table 3). Breathing exercise was the most frequent mode of pain relief $(66.2 \%)$ and only $3(4.8 \%)$ women had epidural labor analgesia.

Table 3. Rating of pain and use of analgesia in previous labor.

\begin{tabular}{lll}
\hline Severity of pain in last confinement $\mathbf{n}=\mathbf{1 1 7}^{*}$ & Frequency & Percentage \\
\hline Mild & 22 & 18.8 \\
Moderate & 40 & 34.2 \\
Severe & 55 & 47.0 \\
& Yes (\%) & No (\%) \\
Any pain relief in previous confinement & $62(53.0)$ & $55(47.0)$ \\
Type of pain relief used $\mathrm{n}=62 \dagger$ & Frequency & Percentage \\
Injection & 18 & 29.0 \\
Breathing exercise & 41 & 66.2 \\
Epidural analgesia & 3 & 4.8 \\
\hline
\end{tabular}

*Number of respondents that had previous confinement (delivery).

'Number of respondents that had pain relief in previous confinement.

Of the 150 respondents, $109(72.7 \%)$ desired to have labor analgesia. A good number of respondents $41(27.3 \%)$ does not desire pain relieve in labor. Most of them 15(36.6\%) believe that labor pain is natural, $11(26.8 \%)$ women believe in divine intervention, $9(22 \%)$ feared side effects, $2(4.9 \%)$ believed they could cope with pain, $3(7.3 \%)$ feared it may affect the baby and $1(2.4 \%)$ had no confidence in pain relieve methods.

The beliefs and perception regarding epidural labor analgesia as expressed by the women is shown in Table 4 . Less than half of the respondents $58(38.7 \%)$ were aware of epidural labor analgesia and $83(55.3 \%)$ desired to have this method of pain relief.

Table 4. Awareness and desire to have epidural analgesia.

\begin{tabular}{lll}
\hline & Yes (\%) & No (\%) \\
\hline Awareness of epidural analgesia in labor & $58(38.7)$ & $92(61.3)$ \\
$\begin{array}{l}\text { Desire to have epidural analgesia in labor } \\
\text { Reasons for not desiring epidural }\end{array}$ & $83(55.3)$ & $67(44.7)$ \\
analgesia n=67 & & \\
Could cope with pain & $8(11.9)$ & \\
No confidence in pain relief methods & $1(1.5)$ & \\
Labor pain is natural & $16(24.9)$ & \\
Faith in divine intervention & $12(17.9)$ & \\
Side effects & $9(13.4)$ & \\
Prolong labor & $2(3.0)$ & \\
Baby may be affected & $19(28.4)$ & \\
\hline
\end{tabular}

The awareness of any method of pain relief in labor (Table 5) and epidural labor analgesia (Table 6) was compared among the socio-demographic groups depicted by age, marital status, tribe, educational level, employment, religion and gravidity. No statistically significant difference was found amongst these groups $(\mathrm{p}<0.05)$.

Table 5. Relationship between socio-demographics and awareness of any pain relief in labor.

\begin{tabular}{lllll}
\hline Variable & $\mathbf{n}=\mathbf{1 5 0}$ & & Test & p-value \\
\hline & Yes & No & Statistics & \\
\hline & $\mathbf{n ~ ( \% )}$ & $\mathbf{n ~ ( \% )}$ & $x \mathbf{2}$ & \\
\hline Age in categories (yrs) & & & & \\
$\leq 30$ & $56(63.6)$ & $32(36.4)$ & 0.086 & 0.770 \\
$>30$ & $38(61.3)$ & $24(38.7)$ & & \\
Marital Status & & & & \\
Married with spouse & $89(64.0)$ & $50(36.0)$ & 1.503 & 0.220 \\
Others & $5(45.5)$ & $6(54.5)$ & & \\
Tribe & & & & \\
Igbo & $88(62.4)$ & $53(37.6)$ & 0.065 & 0.798 \\
Others & $6(66.7)$ & $3(33.3)$ & & \\
Employment & & & & \\
Unemployed & $22(57.9)$ & $16(42.1)$ & 0.495 & 0.482 \\
Employed & $72(64.3)$ & $40(35.7)$ & & \\
Religion & & & & \\
Christianity & $90(62.1)$ & $55(37.9)$ & 0.664 & 0.415 \\
Others & $4(80.0)$ & $1(20.0)$ & & \\
Gravidity & & & & \\
First & $21(63.6)$ & $12(36.4)$ & & \\
$1-2$ & $51(62.2)$ & $31(37.8)$ & 0.022 & 0.989 \\
$\geq 3$ & $22(62.9)$ & $13(37.1)$ & & \\
\hline
\end{tabular}

Table 6. Relationship between socio-demographics and knowledge of epidural analgesia.

\begin{tabular}{|c|c|c|c|c|}
\hline Variable & $n=150$ & & Test & p-value \\
\hline & Yes & No & Statistics & \\
\hline & n (\%) & n (\%) & $\chi 2$ & \\
\hline \multicolumn{5}{|l|}{ Age in categories (yrs) } \\
\hline$\leq 30$ & $31(35.2)$ & $57(64.8)$ & 1.062 & 0.303 \\
\hline$>30$ & $27(43.5)$ & $35(56.5)$ & & \\
\hline \multicolumn{5}{|l|}{ Marital Status } \\
\hline Married with spouse & $56(40.3)$ & $83(59.7)$ & 2.100 & 0.147 \\
\hline Others & $2(18.2)$ & $9(81.8)$ & & \\
\hline \multicolumn{5}{|l|}{ Tribe } \\
\hline Igbo & $54(38.3)$ & $87(61.7)$ & 0.135 & 0.714 \\
\hline Others & $4(44.4)$ & $5(55.6)$ & & \\
\hline \multicolumn{5}{|l|}{ Educational Level } \\
\hline Primary and below & $4(50.0)$ & $4(50.0)$ & 0.458 & 0.499 \\
\hline Secondary and above & $54(38.0)$ & $88(62.0$ & & \\
\hline \multicolumn{5}{|l|}{ Employment } \\
\hline Unemployed & $13(34.2)$ & $25(65.8)$ & 0.426 & 0.514 \\
\hline Employed & $45(40.2)$ & $67(59.8)$ & & \\
\hline \multicolumn{5}{|l|}{ Religion } \\
\hline Christianity & $55(37.9)$ & $90(62.1)$ & 0.993 & 0.319 \\
\hline Others & $3(60.0)$ & $2(40.0)$ & & \\
\hline \multicolumn{5}{|l|}{ Gravidity } \\
\hline First & $10(30.3)$ & $23(69.7)$ & & \\
\hline $1-2$ & $35(42.7)$ & $47(57.3)$ & 1.565 & 0.457 \\
\hline$\geq 3$ & $13(37.1)$ & $22(62.9)$ & & \\
\hline
\end{tabular}




\section{Discussion}

There is poor awareness of women about the use of epidural analgesia in labor. In this study less than half of the respondents $(38.7 \%)$ were aware of epidural labor analgesia even when $92.7 \%$ of the women where multigravida, of which $76 \%$ had their last confinement in the private and tertiary hospitals. Most of the information acquired by the women regarding labor analgesia was gotten from hospital staff. This probably means that not enough information about the role of epidural analgesia in labor is provided to pregnant women attending the antenatal clinic.

The result from this study on awareness of epidural labor analgesia is higher than those of Oladokun et al [16] in the west $(19.5 \%)$ and Iliyasu et al [10] in the north $(8.6 \%)$ of Nigeria. This could be as a result of cultural and religious differences amongst the different regions and ethnic groups in the country. However this is similar to the figures reported from some other developing countries $[7,11,15]$.

Despite the fact that epidural analgesia is seen as the gold standard for labor pain relief in the modern obstetric practice, only few parturient access this pain relief method especially in low socioeconomic settings. In this study only $4.8 \%$ of the respondents had epidural analgesia in previous confinement. The overall epidural labor analgesia rate reported by To et al [17] was $10 \%$ even though $47 \%$ of the antenatal patients had been exposed to the concept of epidural analgesia in labor.

Onah et al [2] found out that parturient in Enugu, south eastern Nigeria, perceive labor as a very painful process with only a minority of them receiving any form of intra-partum analgesia. Most of the respondents $(81.2 \%)$ in this study had moderate to severe pain during labor in previous confinement and only $53 \%$ received some form of pain relief. About two third of these patients received breathing exercise. It is either that there is some apathy towards the demand for analgesia in labor by parturient or reluctance on the part of care givers to suggest or actually give pain medications during labor. In this study $37.3 \%$ of the pregnant women were not aware of any form of pain relief in labor and therefore may not demand for analgesia when they go into labor.

More than half of the respondents $(62.7 \%)$ were aware of labor pain relief methods. This is comparable to the level of awareness of labor analgesia reported by previous studies [7, 11]. Various studies done in Nigeria on the level of awareness of labor analgesia reported $15-64 \%$ [4, 5, 10, 16, 18, 19]. This is similar to what was reported from some other developing countries [11-13, 15].

Majority of our respondents desired to have pain relieve in labor but less than one third does not. This group of women $(27.3 \%)$ believes that labor pain is natural and they don't need any medical intervention but rather believe in divine intervention. This belief was shared by women in similar studies in Nigeria $[18,20]$. Nevertheless, this misconception about labor analgesia needs to be addressed promptly.

The same belief was expressed by the women with respect to epidural labor analgesia. But in addition they feared that it may have detrimental effect on the baby and a few think it may prolong labor [6]. Medical staff should also educate the patients about the side effects of this form of pain relief as some of the fears expressed by the respondents are well established.

In this study Doctors and nurses constitute the source of knowledge to the majority of women who were aware of labor analgesia. Antenatal education classes is very important as prospective parturient are taught what to expect during labor. Only a few respondents gained knowledge from text book and media. This observation is similar to previous studies [7]. However literature has also shown that friends, relatives and information leaflets could also be a major source of information $[6,11]$.

Most of the women interviewed were educated (94.7\%). Awareness of pain relief in labor and epidural labor analgesia was similar among respondents of different age group, marital status, tribe, educational level, employment status, religion and gravidity. The numbers of respondents in each category however are lop-sided and a more balanced population may show the effects of these parameters on awareness of labor analgesia. Previous study has shown significant association between educational status and knowledge of obstetric analgesia [18].

More than half of the women desire to have epidural labor analgesia after receiving information about its role during labor. In order to translate this desire into a higher epidural analgesia rate; there must be a standard epidural analgesia service with a 24-hour coverage; the cost of providing epidural analgesia must be affordable, and the medical resources needed to support the services must be available.

\section{Conclusion}

There is poor level of awareness and utilization of epidural labor analgesia by women in Nigeria. Better dissemination of knowledge of epidural analgesia during the antenatal clinic could increase the proportion of women opting for epidural labor analgesia.

\section{References}

[1] Kuti O, Faponle AF. Perception of labour pain among the Yoruba Ethnic group in Nigeria. J Obstet Gynecol. 2006 26(4): 332-334.

[2] Onah HE, Obi SN, Oguanuo TC, Ezike HA, Ogbuokiri CM, Ezugwuorie JO. Pain perception among parturients in Enugu, South-Eastern Nigeria. J Obstet Gynecol. 2007; 27(6): 585-588.

[3] Owa OO, Alao FO, Faturoti SO, Temenu BA, Lemadoro SA. Acceptability of painless labour among pregnant women in Owo, South-West, Nigeria. Research Obstet gynaecol. 2015; 3(2): $13-16$

[4] Onyeka TC, Chigbu CO. Denial of pain relief during labour to parturients in the South-East Nigeria. Inter J Gynecol Obstet. 2011; 114: 226-228.

[5] Imarengiaye CO, Ande AB. Demand and utilization of labour analgesia service by Nigerian women. J Obstet Gynecol. 2006; 26(2): 130-132. 
[6] Barakazai A, Haider G, Yousuf F, Haider A, Nasiruddin M. Awareness of women regarding analgesia during labour. J Ayub Med Coll Abbottabad. 2010; 22(1): 73-75.

[7] Mugambe JM, Mel M, Hiemstra LA, Steinberg WJ. knowledge of and attitude towards pain relief during labour of women attending the ante-natal clinic of Cecilia Makiwane hospital South Africa. SA Fam Pract. 2007; 49(4): 16

[8] Cambic CR, Wong CA. Labour Analgesia and Obstetric outcome. Brit J Anaesth. 2010; 105(S1): i50- i60.

[9] Brennan F, Carr DB, Cousins M. Pain management: A fundamental human right. Anesth Analg 2007; 105: 205-221.

[10] Iliyasu Z, Galadanci HS, Abubakar IS, Isah H, Aliyu MH. Desire for Obstetric analgesia among women in Northern Nigeria. Trop J Obstet Gynaecol. 2012; 29(2): 53-55.

[11] Mung'ayi V, Nekyon D, Karuga R. Knowledge, attitude and use of labour pain relief methods among women attending ante-natal clinic in Nairobi. East Afr Med J. 2008; 85(9).

[12] Nabukenya MT, Kintu A, Wabule A, Muyingo MT, Kwizera A. Knowledge, attitudes and use of labour analgesia among women at a low income country ante-natal clinic. BMC Anesthesiology. 2015; 15: 98.

[13] Naithani U, Bharwal P, Chauhan SS, Kumar D, Gupta S. Knowledge, attitude and acceptance of antenatal women toward labour analgesia and caesarean section in a medical college hospital in India. J Obstet Anaesth Crit care. 2011; 1(1): 13-20.
[14] Fyneface-Ogan S, Mato CN, Anya SE. Epidural Anaesthesia: Views and outcomes of women in labour in a Nigerian Hospital. Ann Afr Med. 2009; 8(4): 250-256.

[15] Agrawal D, Makhija B, Arora M, Haritwal a, Gurha P. The effect of epidural analgesia on labour, mode of delivery and neonatal outcome in nullipara of India, 2011-2014. J clin diag research. 2014; 8(10): 03-06.

[16] Oladokun A, Eyelade O, Morhason-Bello I, Fadare O, Akinyemi J, Adedokun B. Awareness and desirability of labour epidural analgesia: A survey of Nigerian women. Inter J Obst Anaesth. 2008 18(1): 38-42.

[17] To WWK; The Quality Assurance Subcommittee in Obstetrics and Gynaecology, Hospital Authority, Hong Kong. A questionnaire survey on patients' attitudes towards epidural analgesia in labour. Hong Kong Med J 2007; 13: 208-15.

[18] Okeke CI, Merah NA, Cole SU, Osibogun A. Knowledge and perception of obstetric analgesia among prospective parturients at Lagos University Teaching Hospital. The Nig postgrad med J. 2005; 12(4): 258-261.

[19] Aduloju OP. Pain perception among parturients at a University teaching hospital, South Western Nigeria. Nig Med J.2013; 4(54): 211-216.

[20] Olayemi O, Aimakhu CO, Udoh ES. Attitudes of patients to obstetric analgesia at the University College Hospital, Ibadan, Nigeria. J Obstet Gynecol 2003; 23(1): 38-40. 